\title{
USO DE GEOTECNOLOGIAS PARA IDENTIFICAÇÃO DE ÁREAS VULNERÁVEIS AO DERRAMAMENTO DE PETRÓLEO NA ILHA DO MARANHÃO
}

\section{USE OF GEOTECHNOLOGIES TO IDENTIFY AREAS VULNERABLE TO OIL SPILLS IN THE MARANHÃO ISLAND}

\author{
Thaís de Melo Castelo Branco ${ }^{1}$, Camila Carmona Tavares ${ }^{2}$, Sara Pires Area Leão ${ }^{3}$, \\ Patrícia Tamyres Vergal Sousa ${ }^{4}$, Dr. Denilson da Silva Bezerra ${ }^{5}$
}

Resumo: O derramamento de óleo pode acontecer mesmo com todas as providências de prevenção, a maioria dos acidentes com óleo ocorre em águas costeiras. Este artigo traz uma proposta metodológica para modelagem, espacialmente explícita, baseada em autômatos celulares para simular derramamento de óleo. Inicialmente, foram apresentados o modelo conceitual e os modelos metodológicos para a elaboração dos bancos de dados. A modelagem ocorreu no Golfão Maranhense, localizado no extremo norte do Maranhão. Os dados obtidos foram o uso do solo composto por áreas antropizadas, vegetação de terra firme, manguezal e água e altimetria. $\mathrm{O}$ espaço celular gerado contém 252.443 células, cada autômato tem um estado que a caracteriza como um conjunto de atributos. A simulação, foram propostos os estados e atributos das células regras de transição dos autômatos correlacionados com o modelo conceitual. A compreensão do comportamento da simulação do derrame se torna significativamente útil em tomada de decisão.

Palavras-chave: derramamento de petróleo; Ilha do Maranhão; uso de geotecnologias.

Abstract: The oil spill can happen even with all the precautionnary measures, most oil accidents accur in coastal waters. This paper proposes a methodological proposal for spatially explicit modeling based on cellular automata to simulate oil spillage. Initially, the conceptual model and the methodological models for the elaboration of the databases were presented. The modeling occurred in the Maranhão Golfão located in the extreme north of Maranhão, the data obtained were the use of the soil composed of anthropic areas, terra firme vegetation, mangrove and water and altimetry. The generated cell space contains 252,443 cells, each automaton has a state that characterizes a set of attributes. The simulation, we proposed the states and attributes of the cells transition rules of the automata correlated with the conceptual model. Understanding the behavior of spill simulation become significant useful in decision making.

Key words: island of maranhão; oil spill; use of geotechnologies.

1. Estudante do $9^{\circ}$ período de Engenharia de Petróleo, UniCeuma. E-mail: thamelo@ outlook.com

2. Estudante do $9^{\circ}$ período de Engenharia de Petróleo, UniCeuma.

E-mail: camila.carmona.tavares@gmail.com

3. Estudante do $9^{\circ}$ período de Engenharia de Petróleo, UniCeuma. E-mail:patriciavergal@gmail.com

4. Estudante do $9^{\circ}$ período de Engenharia de Petróleo, UniCeuma. E-mail: leaosara19@ gmail.com

5. Professor Doutor do Mestrado em Meio Ambiente e do curso de Engenharia Ambiental da Universidade Ceuma. E-mail:denilson_ca@yahoo.com.br 


\section{INTRODUÇÃO}

O mundo atual está cada vez mais dependente do petróleo, além de servir como combustível, ainda é matéria-prima para diversos itens e produtos na indústria, sendo então economicamente viável e necessário explorá-lo. Essa atividade está incluída no chamado “desenvolvimento sustentável”, ou seja, o benefício econômico da sua produção ainda compensa seus passivos ambientais, desde que bem gerenciada em seus riscos ecológicos, econômicos e sociais.

Mesmo com todas as medidas de cautela, um derramamento de petróleo pode ocorrer por diversas formas, desde a etapa de produção, transporte e refino. A poluição provocada por petroleiros, embora não seja a maior responsável pela introdução de óleo no mar, resulta em uma maior comoção pública e na concepção de novas legislações (IPIECA, 2010).

O Golfão Maranhense, onde está situado o Porto de Itaqui, possui uma posição estratégica na região nordeste, localizado próximo aos mercados da Europa, América do Norte e Canal do Panamá (EMAP, 2014). Se torna vulnerável a acontecer evento com derramamento de óleo pelo grande tráfego de operações de carga e descarga, a grande maioria dos acidentes com óleo ocorre em águas costeiras. Um prognóstico veloz e preciso do derramamento do óleo oferece noções úteis a criação plana de contenção, a fim de minimizar os danos ambientais e financeiros por esses acidentes (OLIVEIRA, 2009; ZHU et., 2014).

O uso de modelagem computacional constitui uma ferramenta útil para entendimento antecipado de diversas situações como o comportamento de um eventual derramamento de óleo, pois os experimentos de modelagem podem ser entendidos como um laboratório virtual, onde é possível simular os potenciais impactos, antes que os mesmos se manifestem. Tornando significativamente útil, principalmente em áreas de difícil acesso e/ou com pouca produção científica (BERGER et al., 2008).

O objetivo geral do presente trabalho é apresentar uma proposta de metodologia de modelagem dos autômatos celulares para a utilização da simulação hipotética de derramamento de óleo, servindo como auxílio na criação de carta de sensibilidade ambiental para derramamento de óleo. 


\section{MATERIAIS E MÉTODOS}

\section{1. Área de Estudo}

O Golfão Maranhense está situado no extremo norte do Maranhão. E tem em sua formação as baías de São Marcos e São José, que têm ligação distinta com o mar aberto, encontrando-se separados pela ilha de São Luís. Na baía de São Marcos tem a zona costeira marcada por ambiente aquático de transição de rio e mar, as reentrâncias no noroeste do Maranhão, que apresentam cerca de $5.414 \mathrm{~km}^{2}$ de manguezais, e no Nordeste do Pará, com aproximadamente $2.177 \mathrm{~km}^{2}$ de manguezais (SOUZA FILHO, 2005).

\section{Figura 1: Mapa de localização do Golfão Maranhense}

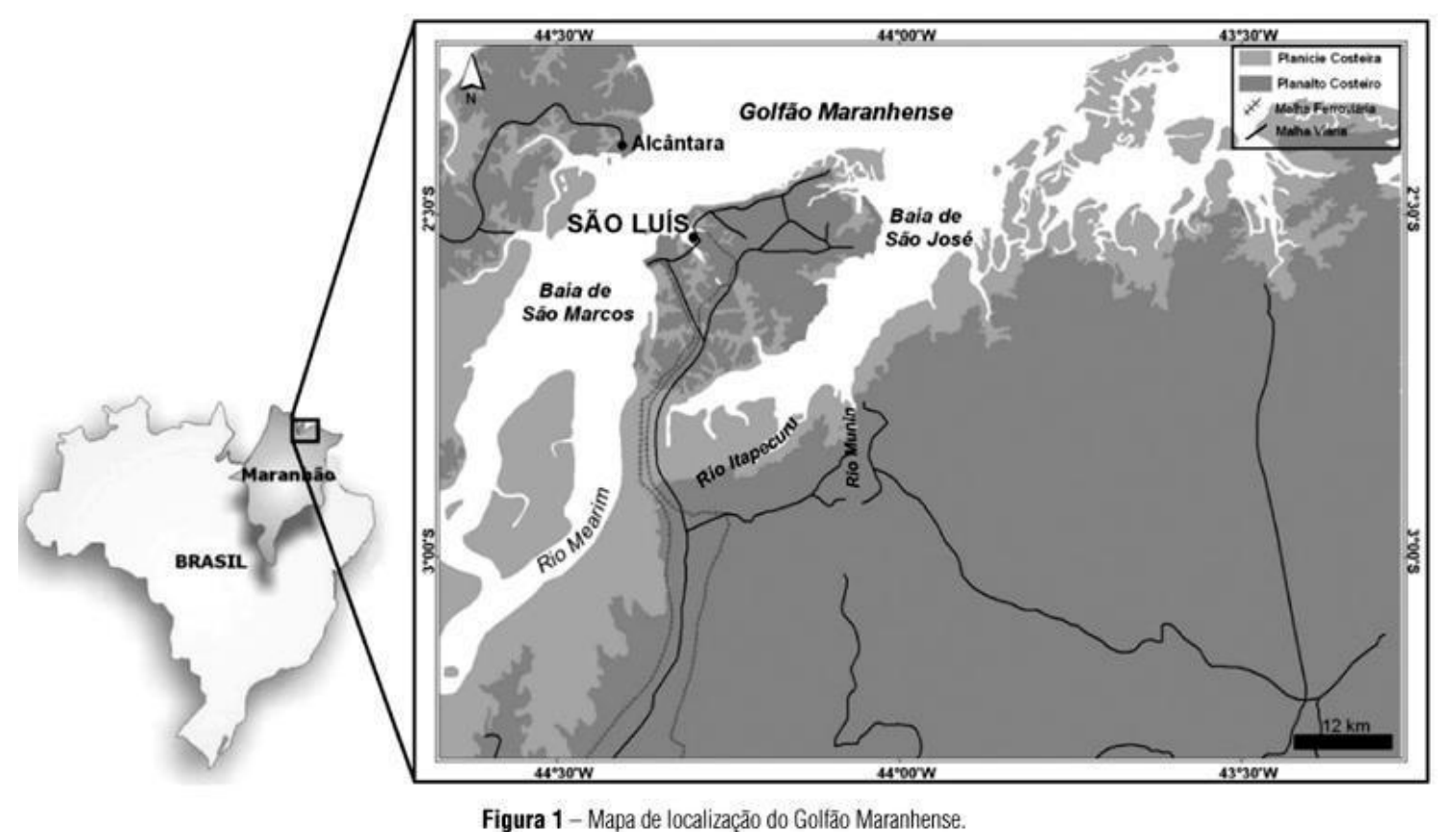

Fonte: Souza Filho, 2005

Nele, estão atribuídos aspectos em parte às diversas características da linha de costa, às grandes quantidades de água doce, provenientes de extensos rios como Itapecuru, Pindaré, Mearim e Munim, às altas taxas de precipitação, bem como às altas amplitudes de maré com alturas de 6 a 7 metros e correntes da ordem de 3 a 4 nós (KJERFVE \& LACERDA, 1993). 
No mapeamento do Ministério do Meio Ambiente, o Golfão Maranhense está localizado na FOZ DO AMAZONAS que ainda está em articulação de andamento das atividades, como mostra o mapa abaixo, para a criação de cartas operacionais, táticas e estratégicas para derramamento de óleo (MMA, 2012):

Figura 2 - Mapeamento da criação das cartas de sensibilidade ambiental para derramamento de óleo

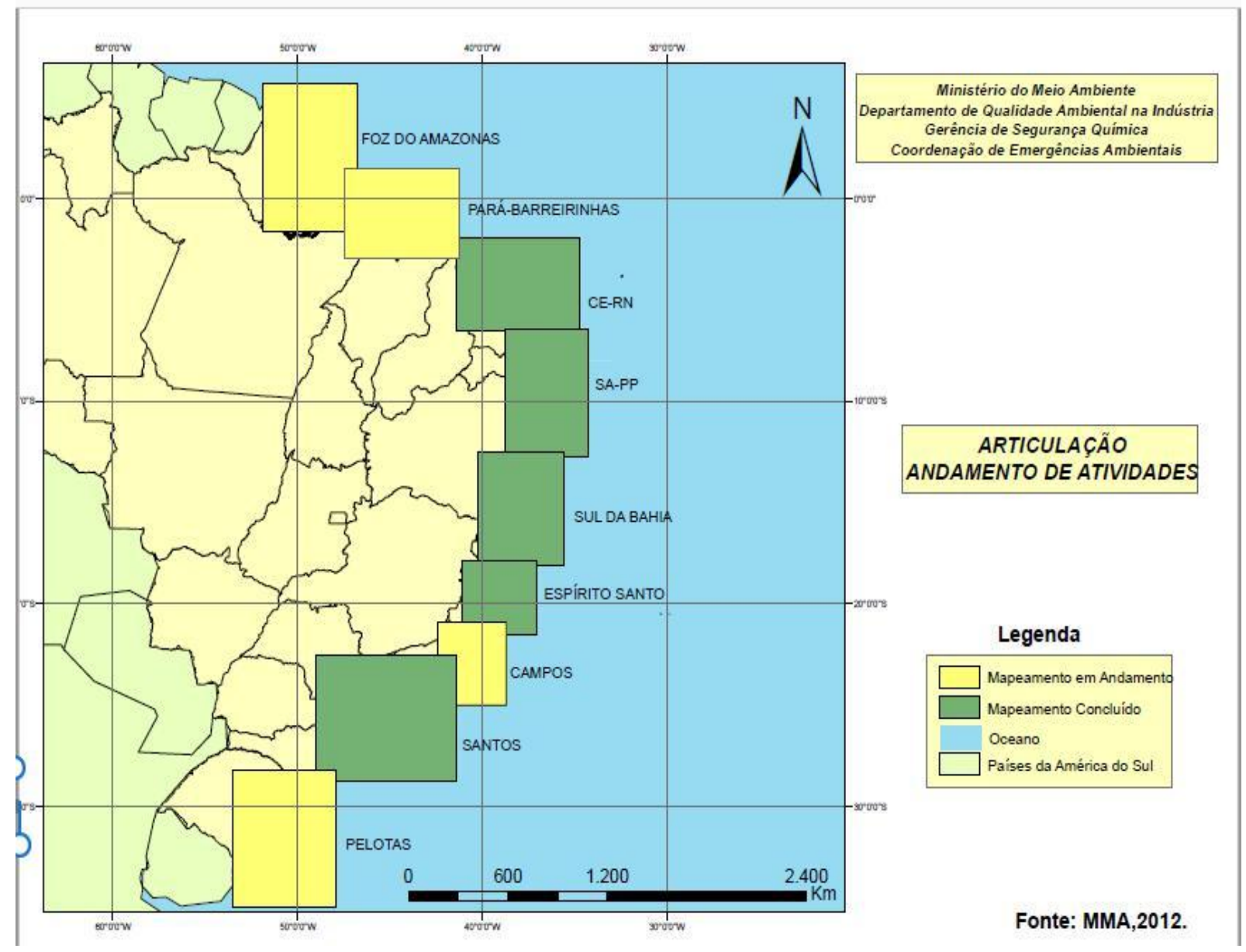

Fonte:Autores.

\subsection{Modelo Conceitual}

A modelagem depende diretamente da base de dados do óleo de fatores como dinâmica do mar, comportamento de óleos derramados nos mais diversos ecossistemas e, principalmente, no mar, depende da composição química do petróleo como também da atuação de processos como 
evaporação, emulsificação, dissolução, biodegradação e das interações entre óleo, sedimentos e água. A rapidez com que o escoamento ganha grande proporção depende das propriedades físicas e químicas do óleo original e das disposições ambientais como: temperatura, velocidade e direção dos ventos e das correntes marinhas. A mais importante modificação ocorrida após o derrame é a evaporação. Em um pequeno intervalo de tempo um petróleo de composição leve pode perder até $75 \%$ de seu volume e os médios até $40 \%$. Isso em ambientes tropicais, pois as temperaturas elevadas fazem com que os componentes voláteis do petróleo sejam evaporados com maior velocidade, diminuindo, assim, os efeitos tóxicos sobre a microflora local (FINGAS, 1998).

Figura 3: Modelo conceitual

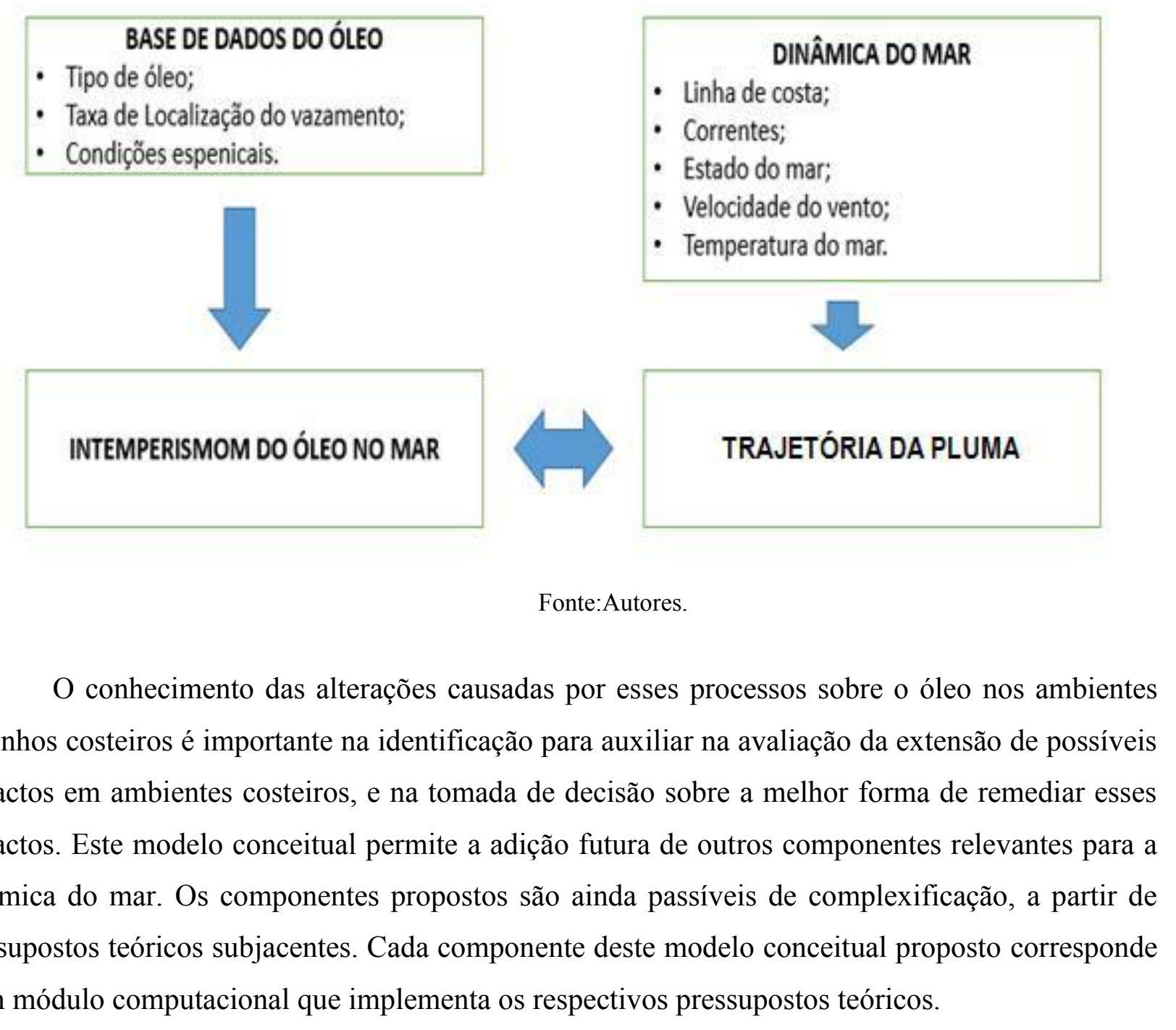




\subsection{Plataforma de Modelagem}

O modelo conceitual foi materializado em um experimento computacional usando a plataforma de modelagem espacialmente explícita integrada com bases de dados geoespaciais TerraME (http://www.terrame.org), desenvolvida pelo Instituto Nacional de Pesquisas Espaciais (INPE) e pela Universidade de Ouro Preto (UFOP). O TerraME é um ambiente para modelagem dinâmica espacial com suporte para modelos baseados em autômatos celulares e agentes com base integrada em um ambiente 2D denominado de espaço celular (CARNEIRO et al., 2013).

O código do modelo conceitual implementado utiliza a linguagem de programação Lua, que uma linguagem livre de código aberto, relativamente simples, porém robusta e com suporte para outras linguagens computacionais, para mais detalhes, acessar o site: http://www.lua.org/.

O procedimento de implementação utilizou o modelo computacional de autômatos celulares, isto é, um modelo baseado em um sistema lógico que tem o conceito de célula como unidade fundamental. Cada célula tem um sistema de vizinhança com as demais células do espaço celular, um estado discreto e atributos que podem variar durante a simulação de acordo com as regras de transição do modelo (WOLFRAM, 1983).

\subsection{Base de dados}

O banco de dados contendo as informações de entrada para o procedimento de modelagem e o espaço celular utilizado para desenvolvimento e aplicação do modelo foram criados em um sistema de informação geográfico desenvolvido pelo Instituto Nacional de Pesquisas Espaciais (INPE), denominado TerraView 4.2.0 (INPE, 2011).

Os dados básicos utilizados para a modelagem foram os Planos de Informação, contendo o mapeamento de uso e cobertura do solo da BHRA para o ano de 2012 realizado pelo Laboratório de Geotecnologias da Universidade Ceuma (LGUC). Os dados obtidos foram: áreas antropizadas, vegetação de terra firme, manguezal e água. O espaço celular criado contém 252.443 células. Como um sistema baseado em autômatos celulares, inicialmente cada célula tem um estado que a caracteriza e um conjunto de atributos. Os estados das células correspondem aos dados obtidos pelo mapeamento do LGUC, e os atributos de todas as células correspondem às classes de solos presentes e a altimetria do Golfão Maranhense obtidos, respectivamente, pelo Núcleo Geoambiental da Universidade Estadual do Maranhão e pelo Banco de Dados Geomorfométricos do Brasil ${ }^{3}$ (TOPODATA), do INPE. 


\section{RESULTADOS E DISCUSSÃO}

O espaço celular utilizado para desenvolvimento e aplicação do modelo foi criado no TerraView 4.2.0, onde foram gerados dois planos de informação, contendo o mapeamento de uso de cobertura do solo e altimetria do Golfão Maranhense. Esses planos continham 252.443 células, correspondendo ao perímetro da área de estudo. Inicialmente, cada autômato celular criado tem um estado que a caracteriza e um conjunto de atributos.

Figura 4: Espaço celular preenchido com as formas de uso e ocupação do solo.

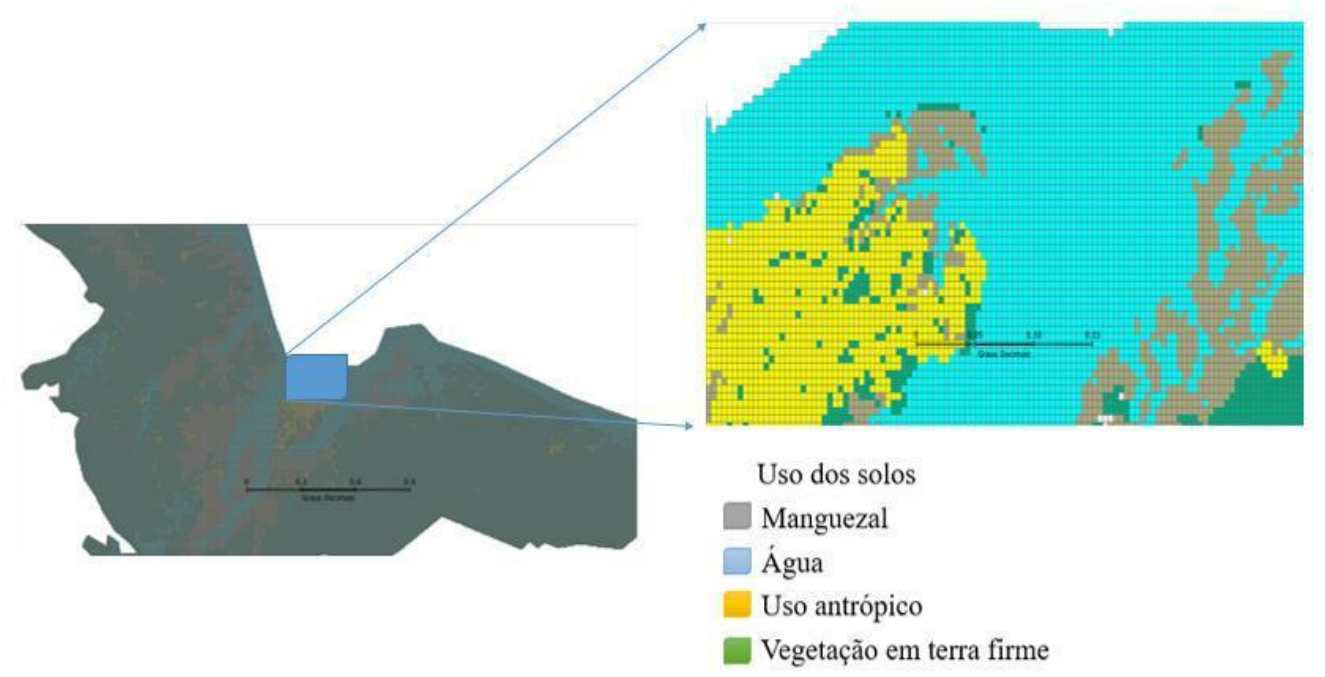

Fonte: Autores.

As características do uso do solo foram agregadas às células por parâmetros distintos, para o modelo de simulação. Para características altimetria de cada célula foram agregados valores em metros (Figura 5).

Figura 5: Espaço celular preenchido com o atributo altimetria (altitude).

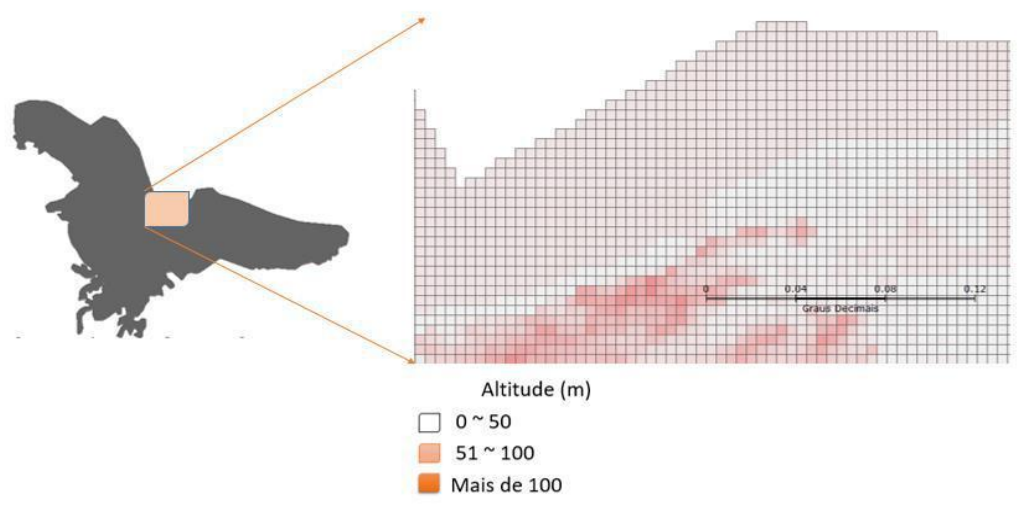

Fonte:Autores. 
Durante os procedimentos de simulação, os estados e os atributos de cada célula podem ser alterados de acordo com as regras de transição do modelo. A situação inicial das formas de uso e escoamento do óleo determina o estado inicial de cada célula como água, mangue, uso antrópico, vegetação de terra firme e praia, contendo seus atributos - altitude e tipo de solo. Os estados e atributos das células, a cada evento do deslocamento do óleo, serão alterados mediante as seguintes regras de transição dos autômatos para a modelagem:

A. Existem água do mar limpa e água do mar contaminada por óleo;

B. O tamanho da pluma de óleo é diretamente proporcional ao tempo e à quantidade em metros cúbicos do derrame;

C. As células do óleo podem migrar com a dinâmica do mar, correntes e variação do vento. Neste caso, as células de água do mar limpas são convertidas em células de água do mar contaminadas;

D. Com a influência da dinâmica do mar, podem ou não chegar nas células de praia e de mangue, onde neste caso as células de água com óleo são convertidas em células de óleo e mangue e solo praia óleo.

\section{CONCLUSÃO}

Por meio dos resultados da modelagem dos autômatos celulares, é possível simular o comportamento da dispersão de óleo, dependendo das características da dinâmica do mar, local da área do eventual derrame, das formas de uso e ocupação do solo, além das taxas de elevação do mar. Esses experimentos de modelagem com autômatos celulares podem ser utilizados no auxílio à tomada de decisão e na formação de medidas para criação de Cartas de Sensibilidade Ambiental a Óleo.

E por fim, os resultados obtidos por meio da proposta sugerem que experimentos de modelagem podem ser usados para promover uma melhor compreensão do comportamento de potenciais eventos para simulação de derramamento de óleo, principalmente em áreas de uso e ocupação complexas como na área objeto do estudo de caso. 


\section{REFERÊNCIAS}

BERGER, U. et al. Advances and limitations of individual-based models to analyze and predict dynamics of mangrove forests, Aquat. Bot, 2008. doi: 10.1016/j.aquabot. 2007.12.015.

CARNEIRO, T.G. et al. 2013. TerraME: an extensible toolbox for modeling nature society interactions. Environmental Modelling \& Software 46: 104-117.

EMAP (Empresa Maranhense de Administração Portuária) -Porto do Itaqui. Infraestrutura. Disponível em: <http:/www.portodoitaqui.ma.gov.br/porto-doitaqui/infraestrutura>. Acesso em: 25 maio.2016.

FINGAS, M.F. The chemistry and physics of oil behaviour at sea: Weathering and incorporation into spill models. Australian U.N. Workshop, 22p, 1998.

INPE. TerraView Software copyright (C) 2001-2011 INPE, Tecgraf PUC-Rio and FUNCATE, 2011.

IPIECA - International Petroleum Industry Environment Conservation Association Against Pollution - A Guide the Intergovernmental and Industry Organizations Involved in the Prevention and Mitigation of Oil Pollution in the Marine Environment. Londres, Reino Unido, 2010. 24 p.

MMA (Ministério do Meio Ambiente) - Cartas de Sensibilidade Ambiental a Derramamentos de Óleo. Disponível em: < http://www.mma.gov.br/seguranca-quimica/cartas-desensibilidade-ao-oleo/base-de-dados >. Acesso em: 25 maio.2016.

KJERFVE B \& LACERDA LD. 1993. Mangroves of Brazil. In: LACERDA LD (Ed.). Conservation and sustainable utilization of mangrove forest in Latin America and Africa regions. Part I - Latin America Mangrove Ecosystem Technical Report No. 2. ITTO/ISME, Okinawa, 272 pp. 
OLIVEIRA, B.; MARIANO, G.; QUADRI,M. “Um estudo CFD de vazamento de óleo a partir de dutos submersos". VII Congresso Brasileiro de Engenharia Química em Iniciação Científica, 2009.

SOUZA FILHO PWM. 2005. Costa de manguezais de macromaré da Amazônia: cenários morfológicos, mapeamento e quantificação de áreas usando dados de sensores remotos. Revista Brasileira de Geofísica. Rio de Janeiro, v.23, n.4, p 427-435.

WOLFRAM, S. Statistical mechanics of cellular automata. Reviews of Modern Physics, Vol. 55, No. 3: 602-644. 1983. 